Check for updates

Cite this: RSC Adv., 2018, 8, 12260

Received 3rd January 2018

Accepted 23rd March 2018

DOI: $10.1039 / \mathrm{c} 8 \mathrm{ra00044a}$

rsc.li/rsc-advances

\section{Bio-distribution and bio-availability of silver and gold in rat tissues with silver/gold nanorod administration $\uparrow$}

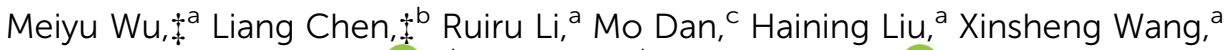 \\ Xiaochun Wu, ${ }^{a}$ Ying Liu, (D) *d Liming $\mathrm{Xu}^{* \mathrm{~b}}$ and Liming Xie (D) *ae
}

\begin{abstract}
Along with the increasing applications of nanomaterials in medical fields, to know the systemic distribution of nanomaterials in the body through a precise method is required for the biosafety assessment of nanomaterials. In this study, we firstly have established a reliable inductively coupled plasma mass spectrometry (ICP-MS) method for concentration measurement of silver (Ag) and gold (Au) in biological tissues. Then, based on this method, the Ag or Au distribution in rat blood and almost all of the organs were analyzed after an i.v. or s.c. administration of Au@Ag NRs. Both the time-dependent contents of Ag and $\mathrm{Au}$ in blood and two pharmacokinetic models confirmed the rapid clearance of $\mathrm{Ag}$ from blood. At $24 \mathrm{~h}$ after i.v. injection, there was the highest level of $\mathrm{Ag}$ in liver, followed by portal nodes, spleen, lung, bone marrow and pancreas. In addition, we also found there were gender-related distributions of Ag and $\mathrm{Au}$ in some organs, especially after s.c. injection. Therefore, these more comprehensive and important results would give fundamental information for the biological risk assessment of nanomaterials.
\end{abstract}

\section{Introduction}

Nanomaterial plays an increasingly important role in our daily life due to its broad applications. For example, silver nanoparticles (AgNPs) have a broad spectrum of antibacterial activity and have been widely applied in various products, including textiles, personal care, cosmetics, home furnishing, appliances,

${ }^{a}$ CAS Key Laboratory of Standardization and Measurement for Nanotechnology, NCNST-NIFDC Joint Laboratory for Measurement and Evaluation of Nanomaterials in Medical Applications, Center for Excellence in Nanoscience, National Center for Nanoscience and Technology, No. 11. Beiyitiao Zhongguancun, Haidian District, Beijing, 100190, P. R. China

${ }^{b}$ Institute for Medical Devices Control, NCNST-NIFDC Joint Laboratory for Measurement and Evaluation of Nanomaterials in Medical Applications, National Institutes for Food and Drug Control, No. 31 Huatuo Road, Biological Medicine Industrial Base, Daxing District, Beijing, 102629, P. R. China. E-mail: xuliming@ nicpbp.org.cn

${ }^{c}$ National Center for Safety Evaluation of Drugs, NCNST-NIFDC Joint Laboratory for Measurement and Evaluation of Nanomaterials in Medical Applications, National Institutes for Food and Drug Control, No. 8 Hongda Mid-Road, Beijing Economic and Technological Development Zone, Daxing District, Beijing 100176, P. R. China

${ }^{d}$ CAS Key Laboratory for Biomedical Effects of Nanomaterials and Nanosafety, NCNSTNIFDC Joint Laboratory for Measurement and Evaluation of Nanomaterials in Medical Applications, Center for Excellence in Nanoscience, National Center for Nanoscience and Technology, No. 11. Beiyitiao Zhongguancun, Haidian District, Beijing, 100190, P. R. China. E-mail: liuy1@nanoctr.cn

${ }^{e}$ University of Chinese Academy of Sciences, Beijing 100049, P. R. China. E-mail: xielm@nanoctr.cn

$\dagger$ Electronic supplementary information (ESI) available. See DOI: $10.1039 / \mathrm{c} 8 \mathrm{ra00044a}$

$\ddagger$ Contributed equally to this work. biomedicine, etc. ${ }^{\mathbf{1 , 2}}$ Gold nanoparticles (AuNPs) have been widely used in biomedical sciences, including drug delivery, imaging, diagnostics and therapies. ${ }^{3-6}$ For the applications of nanomaterials in our daily life, concerns and arguments on the safety of nanomaterials have been raised. ${ }^{7}$ As we know, regardless of administration ways, once nanomaterials get into the body, they could become systemically available. Owing to their extremely small sizes, ingested nanomaterials may be retained in some tissues and cause toxicity. ${ }^{8,9}$ Thereby, the biological safety of nanomaterials is closely related to their concentration to be ingested, distribution and metabolism in the body. ${ }^{10}$ A fundamental question is that, after exposed or administrated with nanomaterials, what concentration of nanoparticles or released ions in the blood is as time elapses and in which organs the nanoparticles or released ions accumulate.

Despite the enormous benefits of AgNPs due to their excellent antimicrobial ability, their health and environmental effects are under intense investigation. Many researchers endeavour to find out what and where AgNPs are in vivo. Large amounts of in vitro experimental evidence have characterized the boilogical responses to AgNPs as their increased exposure to human and environment, but there are only limited literatures in respect of the AgNPs biosafety in vivo. ${ }^{\mathbf{1 1 , 1 2}}$ Thus, too many issues are still unresolved. The systemic distribution of AgNPs is found in almost all in vivo studies even though different administration ways and sizes of AgNPs may be used. However, the distribution patterns and toxicity generated in different animal models could be various. That's why different groups 
may obtain different results. For example, after i.v. injection of AgNPs into rats, some groups found the highest concentration of AgNPs was found in liver, ${ }^{13,14}$ while Recordati C. et al. ${ }^{15}$ reported that the highest silver concentration appeared in spleen. Additionally, the measured silver concentration in blood also varies..$^{\mathbf{8 1 3 , 1 5}}$ The possible reasons about these inconsistent results might be due to a lack of standard analytical methods including digesting biological samples containing nanomaterials besides differences on nanomaterial sizes, administration methods and doses etc. Inductively coupled plasma mass spectrometry (ICP-MS) can give quantitative information about nanomaterial content in various samples with excellent sensitivity and selectivity, ${ }^{\mathbf{1 6 , 1 7}}$ compared to other quantitative detection methods (histotomy, autometallography (AMG) staining, UV-visible, energy dispersive X-ray fluorescence (EDXRF) spectroscopy and atomic absorption spectroscopy (AAS)). ${ }^{15,18-20}$ Therefore, ICP-MS has been widely used in geochemistry, industries, environmental and life sciences, forensic science and archaeology. ${ }^{21}$ In the analysis of biological samples with low target metal concentration, this method needs to be optimized for accurate measurement, especially for the procedures of digesting biological tissues to fully release metal ions. In addition, due to matrix effects and systemic influence, the detection range for specific elements should be considered prior to sample pretreatment and analysis. ${ }^{13}$ However, very few quantitative experiments for nanoparticle content analysis by ICP-MS have given enough consideration for the detection range and accuracy. ${ }^{\mathbf{1 3 , 2 2}}$

So far, there are mainly six kinds of administration ways for the in vivo research of AgNPs. They are oral administration, inhalation exposure, intranasal administration, intravenous (i.v.) injection, subcutaneous (s.c.) injection, intraperitoneal injecttion. AgNPs administrated by the other five ways except i.v. injection finally get into blood and then transfer to other organs. Thus, the bioavailability of these administration ways is very important for the assessment of biosafety of AgNPs exposure. However, there are so few studies related to this problem. Park K et al. ${ }^{14}$ demonstrated that the bioavailability of $1 \mathrm{mg} \mathrm{kg}^{-1}$ AgNPs by oral administration in rats was $1.2 \%$ and in another group orally treated with $10 \mathrm{mg} \mathrm{kg}^{-1}$ AgNPs, the bioavailability was a little higher $4.2 \%$. In addition, in most in vivo studies, researchers only detected $\mathrm{Ag}$ distribution in a few of organs including liver, spleen, kidney, lung, heart, bone marrow and brain..$^{\mathbf{8} 13-15}$ Although these organs are so important for the body, some other organs including lymph nodes can still play a key role in excellent health. If we cannot give comprehensive evaluation of systemic distribution of $\mathrm{Ag}$ in all tissues, the biosafety assessment may not be accurate and reliable for the application of AgNPs.

Therefore, in this study, we optimized sample digestion procedures to carefully test the detection range for silver (Ag) and gold $\mathrm{Au}$ ) in biological samples. In order to minimize the sediment of $\mathrm{Ag}$ ion caused by $\mathrm{HCl}$ and elevate the $\mathrm{Ag}$ ion recovery in organic samples, we optimized the ratio of nitrichydrochloric mixed acid to 9:1 in the digestion process. Further, the well-established ICP-MS protocol was used to analyze biokinetics of $\mathrm{Ag}$ and $\mathrm{Au}$ in blood and their distribution in most organs of rats after a single intravenous (i.v.) or subcutaneous (s.c.) injection of $\mathrm{Ag} / \mathrm{Au}$ nanorods (NRs). This nanomaterial is silver nanorods (NRs) composed of gold cores and silver shells (Au@Ag NRs). ${ }^{16}$ Gold as an internal reference due to its inert in biological environment can track the NRs in vivo so as to evaluate the dissolution of silver shells. However, the reason of choosing the intravenous route of administration is to avoid a number of potentially confounding factors by other extravascular administration. ${ }^{8}$ Moreover, since AgNPs are largely applied in wound dressing, subcutaneous administration could simulate the wound situation. In addition, in our study, the bioavailability of subcutaneous-administrated Au@Ag NRs was also evaluated by the construction of two pharmacokinetic models. Here, we have to address that nanostructures with different shapes may display some differences in pharmacokinetic profiles and tissue distribution. ${ }^{23,24}$ Although the results of Au@Ag NRs cannot be totally regarded as that of AgNPs in vivo, they have some similarities including the dissolution of $\mathrm{Ag}$ or the release of $\mathrm{Ag}$ ions. Therefore, our results would provide comprehensive and valuable information about the accumulation and metabolism of AgNPs as well as AuNPs in the biological study.

\section{Experimental}

\subsection{Reagents and materials}

Chloroauric acid $\left(\mathrm{HAuCl}_{4} \cdot 3 \mathrm{H}_{2} \mathrm{O}\right)$, sulphuric acid $\left(\mathrm{H}_{2} \mathrm{SO}_{4}\right)$, sodium chloride $(\mathrm{NaCl})$, and silver nitrate $\left(\mathrm{AgNO}_{3}\right)$ were purchased from Beijing Chemical Reagent Company (Beijing, China). All chemicals used for digestion and ICP-MS were of metal-oxide-semiconductor (MOS) grade or of high purity. Nitric acid $\left(\mathrm{HNO}_{3}\right)$ and hydrochloric acid $(\mathrm{HCl})$ were purchased from Beijing Institute of Chemical Reagents (Beijing, China). The standard solution of silver $(\mathrm{Ag})$ ion and gold $(\mathrm{Au})$ ion as well as indium (In) ion used as the internal standard were purchased from ALADDIN (Shanghai, China), Acros Organics (Geel, Belgium) and Melone-pharma (Dalian, China), respectively. Gold nanoparticles (AuNPs, $40 \mathrm{~nm}$ ) were purchased from BBI Solutions (Cardiff, UK). Deionized water $(18 \mathrm{M} \Omega \mathrm{cm})$ was used in all the preparations.

\subsection{Preparation of gold core/silver shell nanorods (Au@Ag NRs) and $40 \mathrm{~nm}$ AgNPs}

The gold core/silver shell nanorods (Au@Ag NRs) were synthesized by a seed-mediated growth method as described in the ref. 25. Silver nanoparticles (AgNPs, $40 \mathrm{~nm}$ ) were also synthesized by seed growth strategy. In brief, $0.25 \mathrm{~mL}$ of $\mathrm{AgNO}_{3}(0.1 \mathrm{M})$ was injected into the boiling $5 \mathrm{~mL} 0.1 \mathrm{M}$ sodium citrate (SC) and $0.25 \mathrm{~mL} 0.1 \mathrm{M}$ tannic acid (TA) mixture solution to prepare $\sim 15 \mathrm{~nm}$ silver seeds. Then, $900 \mathrm{~mL}$ deionized water was added, the reaction temperature was set to $90{ }^{\circ} \mathrm{C}$ before $5 \mathrm{~mL}$ of SC $(0.1$ M), $0.75 \mathrm{~mL}$ of TA $(0.1 \mathrm{M})$, and $5 \mathrm{~mL}$ of $\mathrm{AgNO}_{3}(0.1 \mathrm{M})$ were sequentially injected with a time delay of $\sim 1 \mathrm{~min}$. After growing $30 \mathrm{~min}$, the injection of $\mathrm{SC}$, TA and $\mathrm{AgNO}_{3}$ was repeated once and the reaction continued for another hour. The final AgNPs 
were purified by centrifugation twice $(9500 \mathrm{rpm}, 20 \mathrm{~min})$. The precipitate was re-dispersed in $200 \mathrm{~mL}$ deionized water.

\subsection{Determination of detection limit of ICP-MS for blood and tissue samples}

The systemic interference on ICP-MS measurement was studied by the recovery calculation of $\mathrm{Ag}$ or $\mathrm{Au}$ standard ion solution containing a series of $\mathrm{Ag}$ or Au with the known absolute amount from 0.001 to $100 \mu \mathrm{g}$. For studying the matrix effects on nanoparticles recovery, we used $40 \mathrm{~nm}$ AgNPs or $40 \mathrm{~nm}$ gold nanoparticles (AuNPs) to test the detection limit of $\mathrm{Ag}$ or Au content in rat tissues. In details, about $0.2 \mathrm{~g}$ of blood or liver from blank male rats in the polyfluortetraethylene digest vessels was mixed with AgNPs or AuNPs solution containing the predetermined amount $\mathrm{Ag}$ or $\mathrm{Au}$ (0.001-100 $\mu \mathrm{g})$. Then, all samples were prepared for ICP-MS measurement and the recovery yields of silver and gold were analyzed to determine the lower limit of detection (LOD).

\subsection{Characterization of Au@Ag NRs}

The morphology, sizes and energy dispersive X-ray spectroscopy (EDS) mapping of Au@Ag NRs was acquired by transmission electron microscopy (TEM, JEM-2100F, Hitachi, Tokyo, Japan) at an acceleration voltage of $200 \mathrm{kV} .6 \mu \mathrm{L}$ NRs solution in Milli-Q water were dropped onto a cupper grid and dried at room temperature before observation. The UV/visible/near infrared (UV/vis/NIR) spectrophotometer (Lambda 950, Perkin Elmer Instruments Co. Ltd., USA) was used for measuring the NRs from $200 \mathrm{~nm}$ to $1100 \mathrm{~nm}$. Au@Ag NRs zeta potential was measured by dynamic light scattering (DLS) (Zetasizer Nano ZS, Malvern, UK) in clear disposable zeta cell. The samples including $10 \mu \mathrm{g} \mathrm{mL} \mathrm{m}^{-1}$ of Ag were dispersed in deionized water at $25{ }^{\circ} \mathrm{C}$ before measurement. The results were reported as the average of 3 measurements, in which each measurement contained 12 individual runs.

\subsection{Animal experiment}

Sprague Dawley (SD) rats of 6-8 weeks old were maintained under specific pathogen-free conditions in the Experimental Animal Center of National Institutes for Food and Drug Control (Beijing, China), and the protocol for animal experiment was reviewed and approved by the Institutional Review Board. The rats were acclimatized to laboratory conditions for 1 week prior to the experiment, and then divided into 2 groups which were exposed to Au@Ag NRs through intravenous and subcutaneous injection, respectively. Each group included 16 rats, male and female in half. The average body weight of male and female rats at the beginning of the experiment is $143.4 \pm 5.8 \mathrm{~g}$ and $149.4 \pm$ $8.2 \mathrm{~g}$, respectively, and no significant differences between male and female. Here, the i.v. administration was selected to avoid the absorption variability from different exposure sites and identify the potential target organs for Au@Ag NRs or released Ag ions. ${ }^{15}$ The Au@Ag NRs were centrifuged and resuspended in deionized water. The injected volume per rat was $500 \mu \mathrm{L}$, containing $\mathrm{Ag}$ of $0.6 \mathrm{mg}$ and $\mathrm{Au}$ of $0.34 \mathrm{mg}\left(1.7 \times 10^{-3} \mathrm{nmol} \mathrm{NRs}\right)$. Before injection and at the indicated times after intravenous exposure ( $3 \mathrm{~min}, 10 \mathrm{~min}, 30 \mathrm{~min}, 1 \mathrm{~h}, 2 \mathrm{~h}, 4 \mathrm{~h}, 8 \mathrm{~h}, 16 \mathrm{~h}$, day 1 , day 2 , day 4 , day 7 , day 14 ) and subcutaneous exposure (30 min, $2 \mathrm{~h}, 4 \mathrm{~h}, 8 \mathrm{~h}, 16 \mathrm{~h}$, day 1 , day 2 , day 3 , day 5 , day 7 , day 10 , day 14), blood samples for ICP-MS analysis were collected from two different groups which were day $0-1$ and day 2-14 group, respectively. In each group, there were 8 rats ( 4 males and 4 females). The blood was collected from the eye socket of rats and added into an Eppendorf tube containing anticoagulant, and then kept in $-80^{\circ} \mathrm{C}$. Furthermore, on day 1 and day 14,8 rats ( 4 males and 4 females) from each group were sacrificed from which the organs were collected and kept in $-80^{\circ} \mathrm{C}$. The blank organs for the baseline detection of $\mathrm{Ag}$ or $\mathrm{Au}$ were from four non-treated female and non-treated male rats, respectively.

\subsection{Sample digestion prior to ICP-MS measurement}

About $0.2 \mathrm{~g}$ blood or tissue was weighed in each measurement and added into $10 \mathrm{~mL}$ of a mixture of concentrated $\mathrm{HNO}_{3}$ and HCl $(9: 1)$ in a PFA digestion vessel. All vessels were shortly shaken by hand and capped for pre-dissolution overnight. Then, all samples were digested by a microwave digestion instrument (MARS, CEM, Matthews, NC, USA). The microwave heating programs for digestion were $120{ }^{\circ} \mathrm{C}(2 \mathrm{~min})-160{ }^{\circ} \mathrm{C}(5$ $\min )-195{ }^{\circ} \mathrm{C}(50 \mathrm{~min})$. When the vessels were cooled down, the digested products were heated to about $150{ }^{\circ} \mathrm{C}$ in a heating block (BHW-09C, BOTONYC, Shanghai, China) to drive off the vapor of $\mathrm{HCl}$ and nitrogen oxides and then diluted with $1 \%(\mathrm{v} / \mathrm{v})$ $\mathrm{HNO}_{3}$ (for $\mathrm{Ag}$ ) or $1 \%(\mathrm{v} / \mathrm{v}) \mathrm{HNO}_{3}$ and $1 \%(\mathrm{v} / \mathrm{v}) \mathrm{HCl}$ (for $\mathrm{Au}$ ) to a final acid concentration of $\sim 3 \%$ before ICP-MS measurement. Each sample was prepared in triplicates.

\subsection{Measurement with ICP-MS}

All prepared standards and samples were measured by ICP-MS system (NexION 300X, Perkin Elmer, USA). Quantification was carried out with In element ( $25 \mathrm{ppb}$ ) internal standard correction. The main operating conditions for ICP-MS were as follows: the radio frequency $(\mathrm{RF})$ power $1600 \mathrm{~W}$; argon gas flow rates for the plasma, auxiliary, and nebulizer flow were $18 \mathrm{~L} \mathrm{~min}^{-1}, 1.2$ $\mathrm{L} \min ^{-1}$, and $0.98 \mathrm{~L} \mathrm{~min}^{-1}$, respectively.

\subsection{Pharmacokinetic modeling}

Non-compartmental analyses of the whole blood $\mathrm{Ag}$ or $\mathrm{Au}$ concentrations versus time results were conducted using WinNonLin, a pharmacokinetic analysis program (Pharsight@, St. Louis, MI, USA). Non-compartmental method used to calculate pharmacokinetic parameters did not assume the number of compartments. For non-compartmental analysis, area under the concentration-time curve $\left(\mathrm{AUC}_{\text {last }} ; \mathrm{h} \mathrm{mg} \mathrm{L}{ }^{-1}\right)$, maximum concentration $\left(C_{\max } ; \mathrm{mg} \mathrm{L}^{-1}\right)$, half-life $\left(t_{1 / 2}, \mathrm{~h}\right)$, and mean residence time (MRT, h) were calculated. The squared correlation of distances $\left(R_{\mathrm{Sq}}\right)$ and correlation between time $(X)$ and $\mathrm{Ag}$ or $\mathrm{Au}$ concentrations $(Y)$ (Corr- $X Y)$ were used to measure the goodness of fit. $\mathrm{AUC}_{\text {last }}$ was calculated by using the trapezoidal rule without making any assumption concerning the number of compartments. The terminal half-life $t_{1 / 2}$ was readily estimated from the terminal slope $\lambda$ as $t_{1 / 2}=\ln (2) / \lambda$. Compartmental analyses of the whole blood $\mathrm{Ag}$ or Au concentrations versus time 
results were conducted using WinNonLin. Two-compartment model included a central compartment (blood and wellperfused organs) and a peripheral compartment (poorlyperfused tissues) to which the drug may distribute. The blood concentration time curve did not decline smoothly as a linear line but as two different phases (i.e. distribution and elimination). For two-compartmental analysis, area under the concentration-time curve $\left(\mathrm{AUC}_{\text {last }} ; \mathrm{h} \mathrm{mg} \mathrm{\textrm {L } ^ { - 1 }}\right)$, maximum concentration $\left(C_{\mathrm{max}} ; \mathrm{mg} \mathrm{L}^{-1}\right)$, first half-life $\left(t_{1 / 2}, \mathrm{~h}\right)$, second half-life $\left(t_{1 / 2}, \mathrm{~h}\right), V_{\mathrm{ss}}$ $(\mathrm{mL})$, and mean residence time (MRT, h) were calculated. Goodness of fit was based on visual inspection, weighted corrected sum of squares, sum of square residuals, weighted sum of square residuals, random distribution of residuals, Akaike's information criteria and Swartz criteria. The initial estimates for model parameters were calculated as below. The semilogarithmic plots of blood concentration $v s$. time data showed the two-compartment kinetic model as $C(t)=\mathrm{R} 1 \mathrm{e}^{-\lambda_{1} t}+\mathrm{R} 2 \mathrm{e}^{-\lambda_{2} t}$. $\mathrm{R} 1$ and $\mathrm{R} 2$ represent intercepts on the concentration $(Y)$ axis of the back-extrapolated initial and terminal phases, respectively. $\lambda_{1}$ and $\lambda_{2}$ were the initial and terminal slopes, respectively. The elimination half-lives $\left(t_{1 / 2}\right)$ were calculated as $t_{1 / 2 \lambda_{1}}=\ln (2) / \lambda_{1}$ and $t_{1 / 2 \lambda_{2}}=\ln (2) / \lambda_{2}$. MRT was calculated as MRT $=$ AUMC/AUC. $V_{\mathrm{ss}}$ was calculated as $V_{\mathrm{ss}}=D_{\mathrm{ss}} / C_{\mathrm{pss}}\left(D_{\mathrm{ss}}\right.$ : the amount of drug in the body at steady state; $C_{\mathrm{pss}}$ : the blood concentration). ${ }^{\mathbf{2 6}}$

\subsection{Statistical analysis}

All of the data are presented as mean \pm standard deviation. Statistical analysis was performed using One-Way ANOVA, and $p$ $<0.05$ was considered as statistically significant different between male and female groups after s.c. injection.

\section{Results and discussion}

\subsection{Characterization of Au@Ag NRs}

Au@Ag NRs were characterized for their physicochemical properties by TEM, UV/vis/NIR spectroscopy and DLS. TEM images showed that Au@Ag NRs were a kind of nanorods with uniform sizes (Fig. 1A). The average length and diameter of $\mathrm{Au}$ NRs@Ag were $73.4 \pm 3.2 \mathrm{~nm}, 34.6 \pm 1.9 \mathrm{~nm}$ (Fig. S1†). And according to TEM images, it can be found that the surface of gold nanorods (AuNRs) was homogeneously covered by a thin layer of $\mathrm{Ag}$ with a thickness of $7.7 \pm 1.0 \mathrm{~nm}$ (Fig. S1†). Au@Ag NRs were further characterized with energy dispersive X-ray spectroscopy (EDS). The EDS spectrum verified that the NRs composed of element Au and Ag (Fig. 1B). Moreover, the EDS mapping results also evidenced that a layer of $\mathrm{Ag}$ wrapped up the AuNRs (Fig. 1C). Other physicochemical characterization was provided in ESI (Fig. S2 $\dagger$ ).

\subsection{Limit of detection (LOD) of $\mathrm{Ag}$ and Au in biological samples by ICP-MS}

Before exploring the accurate concentration range of $\mathrm{Ag}$ as well as Au detected by ICP-MS, we first checked the recovery yields of $\mathrm{Ag}$ and $\mathrm{Au}$ by testing standard $\mathrm{Ag}$ and $\mathrm{Au}$ ion solution all through the process. The detection limit is determined as the lowest concentration within an absolute error within $\pm 20 \%$. As
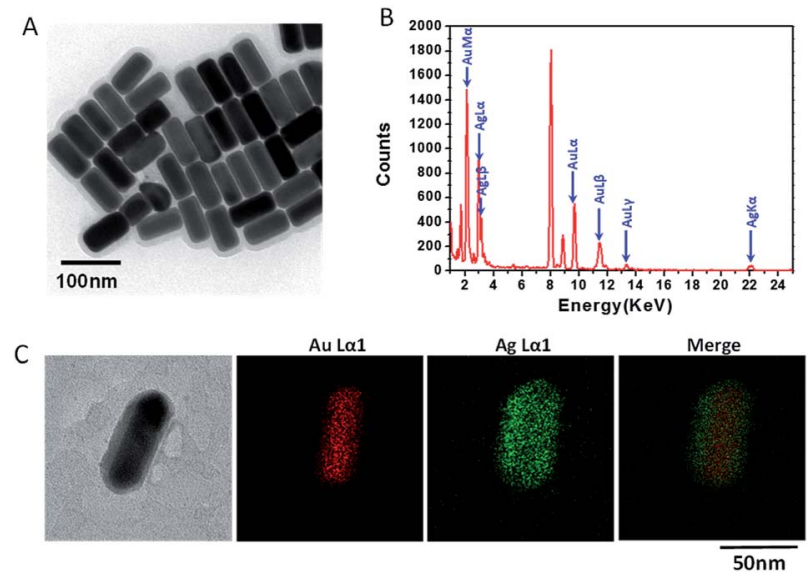

Fig. 1 Physicochemical characterization of Au@Ag NRs used in animal experiments. (A) A representative TEM image. (B) EDS analysis. (C) EDS mapping image.

shown in Fig. S3, $\uparrow$ the LOD of Ag as well as Au was $0.003 \mu \mathrm{g}$ and $0.005 \mu \mathrm{g}$, respectively. Further, the biological matrix effects on the accuracy of ICP-MS measurement were investigated by measuring nanoparticle solution at known concentrations mixed with blood or liver. Fig. 2 showed the detected values of $\mathrm{Ag}$ or $\mathrm{Au}$ content for a series amount of AgNPs or AuNPs from $0.001 \mu \mathrm{g}$ to $100 \mu \mathrm{g}$ mixed with $\sim 0.2 \mathrm{~g}$ blood or liver matrix from blank rats. The LOD for AgNPs in liver tissue and in blood sample detected by ICP-MS was $0.020 \mu \mathrm{g} \mathrm{g}^{-1}$ and $0.005 \mu \mathrm{g} \mathrm{g}^{-1}$, respectively (Fig. 2A and B). And the LOD of AuNPs in both liver tissue and blood sample was measured to be $0.015 \mu \mathrm{g} \mathrm{g}^{-1}$ (Fig. 2C and D). The low recovery yield of $\mathrm{Ag}$ or $\mathrm{Au}$ at the lower concentration may be due to the absorption of silver ions and/or nanoparticles onto the surface of instrument or vessels.
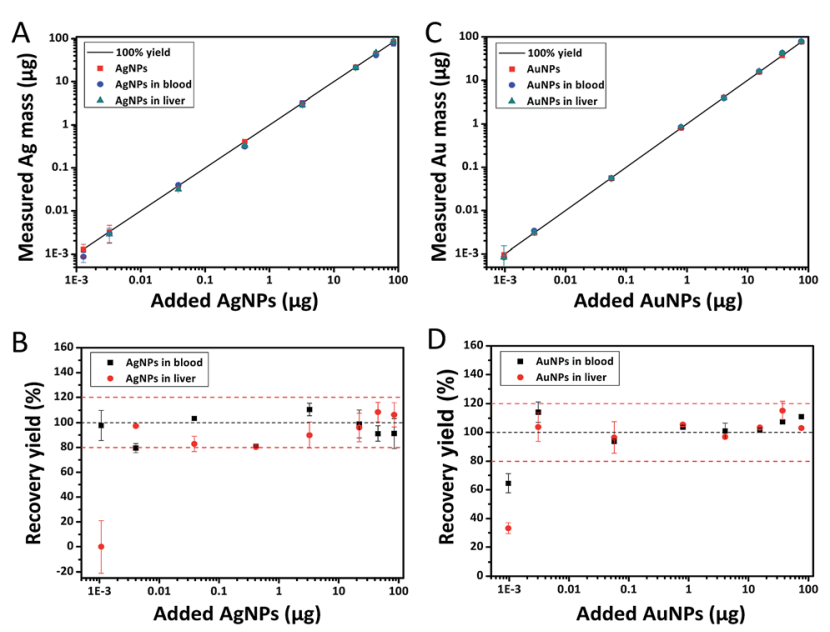

Fig. 2 The detection range of nanoparticles in biological tissues. $0.001-100 \mu \mathrm{g}$ of $40 \mathrm{~nm}$ silver (A and B) or gold nanoparticles (C and D) were mixed with about $0.2 \mathrm{~g}$ liver or blood from blank rats before microwave digestion and ICP-MS measurement ( $n=3$ for each concentration). (A and C) Measured mass of nanoparticles with or without tissues. ( $B$ and D) The recovery yield of nanoparticles. Black line: the recovery yield of $100 \%$. Red line: the recovery yield of $100 \pm$ $20 \%$. 


\subsection{Ag and Au contents in rat blood after Au@Ag NRs} injection

Since their efficacy largely depends on the control of their distribution within the body for the medical applications of nanomaterials, it is so important to illustrate the concentration-time profiles in blood and organs of interest. Our wellestablished ICP-MS method can be used to accurately measure $\mathrm{Ag}$ and $\mathrm{Au}$ concentrations in animals after nanorod injection. We carried out a single i.v. or s.c. injection of Au@Ag NRs in SD rats. Blood samples collected at predetermined time intervals after injection were prepared for ICP-MS measurement (Fig. 3A and 4A). All measured data were corrected by the blank value. For i.v. injection, the content of $\mathrm{Ag}$ as well as $\mathrm{Au}$ in blood reached its maximum value at about $3 \min (15.81 \pm 6.03$

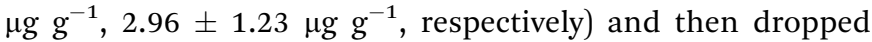
dramatically, which displayed a similar trend to other reports. ${ }^{8,13}$ From $10 \mathrm{~min}$ to $14 \mathrm{~d}$ after injection, there were extremely low levels of Ag (Fig. 3B) and Au (Fig. 3C), suggesting no accumulation of $\mathrm{Ag}$ in blood. The concentration-time profile of Au@Ag NRs by i.v. administration showed that Au@Ag NRs could be rapidly cleared out from blood and transfer to various organs within $1 \mathrm{~h}$ and after that there would be an equilibrium of distribution. ${ }^{8}$ For s.c. injection, we observed a quite different scenario. The content of $\mathrm{Ag}$ as well as Au was far below that after i.v. injection in blood (Fig. 4B and C), suggesting that the majority of Au@Ag NRs after the s.c. administration did not go into blood circulation. The $\mathrm{Ag}$ content in blood increased slowly at $4 \mathrm{~h}$ and reached to the maximum of $0.70 \pm 0.17 \mu \mathrm{g} \mathrm{g}^{-1}$ at $2 \mathrm{~d}$ after s.c. injection. At 14 $\mathrm{d}$ after injection, the level of $\mathrm{Ag}$ was still relatively high $(0.24 \pm$ $0.01 \mu \mathrm{g} \mathrm{g}^{-1}$ ). In sharp contrast, the Au content was very low from the beginning to $14 \mathrm{~d}$ after s.c. injection (Fig. 4C). These results show that the whole Ag@Au NRs can rarely ingested and transported into the blood but can release $\mathrm{Ag}$ ion $\left(\mathrm{Ag}^{+}\right)$ into blood. Here, Au ion cannot be released into blood due to its high oxidation potential $\left(1.498 \mathrm{~V}\right.$ for $\mathrm{Au}^{3+} / \mathrm{Au}$, in contrast $0.2223 \mathrm{~V}$ for $\left.\mathrm{Ag}^{+} / \mathrm{Ag}\right)$.
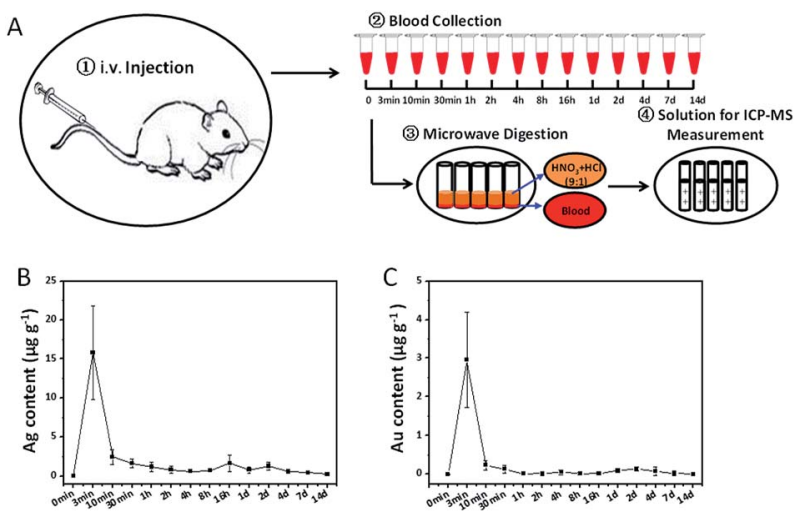

Fig. 3 Contents of $\mathrm{Ag}$ and $\mathrm{Au}$ in blood after i.v. injection. (A) The flowchart of experimental procedures. (B) Average content of $\mathrm{Ag}$ in blood at different time points. (C) Average content of $\mathrm{Au}$ in blood at different time points. ( $n=8,4$ males and 4 females). All data were deducted by the background value from the blank blood.
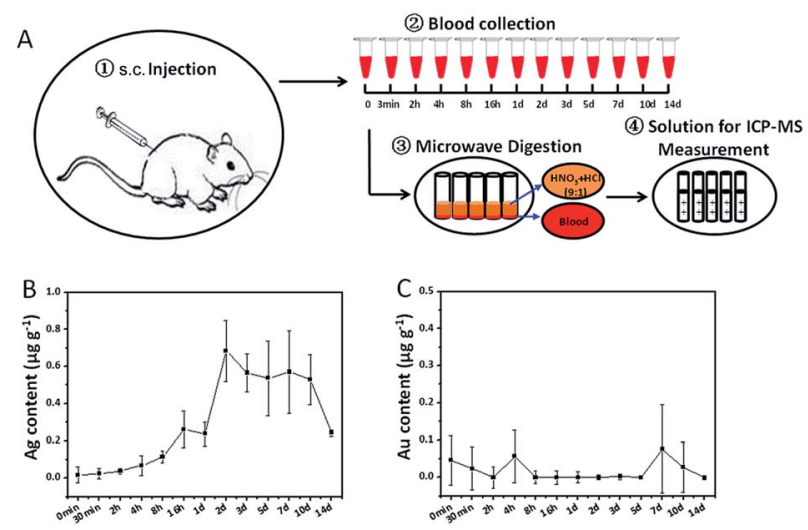

Fig. 4 Contents of $\mathrm{Ag}$ and $\mathrm{Au}$ in blood after s.C. injection. (A) A flowchart of experimental procedures. (B) Average content of Ag in blood at different time points. (C) Average content of $\mathrm{Au}$ in blood at different time points. ( $n=8,4$ males and 4 females). All data were deducted by the background value from the blank blood.

\subsection{Pharmacokinetic of Au@Ag NRs in rats}

The measured $\mathrm{Ag}$ and $\mathrm{Au}$ concentrations in blood and organs can be quantitatively analyzed to get bioavailability of Au@Ag NRs in rats. Pharmacokinetic models were constructed using the detected $\mathrm{Ag}$ or $\mathrm{Au}$ concentrations in whole blood from each individual rat's results. Non-compartmental models showed the best fits for $\mathrm{Ag}$ concentrations from nanorods after i.v. injection $\left(R_{\mathrm{sq}}=0.94\right.$; Corr $\left.X Y=-0.97\right)$. Fig. S4 $\uparrow$ showed the calculated model versus the obtained $\mathrm{Ag}$ concentrations for the i.v. group using non-compartmental model. However, Au concentrations from the nanorods after i.v. injection and $\mathrm{Ag}$ concentrations from nanorods after s.c. injection were poorly fitted by noncompartmental models. Detailed results were showed in Table 1 . The $C_{\max }$ in the i.v. group was 19 times higher than the s.c. group. However, after $14 \mathrm{~d}$ (336 h), silver concentrations were also similar between the i.v. group and s.c. group. On the premise of a rapid clearance of $\mathrm{Ag}$ from plasma, the subcutaneous exposure of $\mathrm{Ag}$ in $\mathrm{Au} @ \mathrm{Ag}$ NRs was about $78.9 \%$ of i.v. exposure calculated by s.c. $\mathrm{AUC}_{\text {last }} /$ i.v.AUC ${ }_{\text {last }}$. In general, the AUC ratio within $80-125 \%$ is considered as bioequivalence. ${ }^{27}$ Silver exposure in the s.c. group was slightly lower than its exposure in the i.v. group. The results demonstrated that the routes of administration did not influence silver exposures of nanorods. For i.v. administration, $C_{\max }\left(15.85 \mathrm{mg} \mathrm{L}^{-1}\right)$ of $\mathrm{Ag}$ was reached $0.05 \mathrm{~h}$ after injection. However, after $240 \mathrm{~h}$ of injection, $C_{\text {max }}$ of $\mathrm{Ag}$ was $0.84 \mathrm{mg} \mathrm{L}^{-1}$ for s.c administration. This result shows that silver has different kinetics between i.v. and s.c. administrations. As shown in Fig. 3, the blood concentration

Table 1 Pharmacokinetic parameters from the noncompartmental model

\begin{tabular}{llllll}
\hline & $\begin{array}{l}T_{\max } \\
(\mathrm{h})\end{array}$ & $\begin{array}{l}C_{\max } \\
\left(\mathrm{mg} \mathrm{L}^{-1}\right)\end{array}$ & $\begin{array}{l}t_{1 / 2} \\
(\mathrm{~h})\end{array}$ & $\begin{array}{l}C_{\text {last }} \\
\left(\mathrm{mg} \mathrm{L}^{-1}\right)\end{array}$ & $\begin{array}{l}\mathrm{AUC}_{\text {last }} \\
\left(\mathrm{h} \mathrm{mg} \mathrm{L}^{-1}\right)\end{array}$ \\
\hline Ag after i.v. & 0.05 & 15.85 & 112 & 0.28 & 258.65 \\
Au after i.v. & 0.05 & 2.51 & - & 0.32 & 92.55 \\
Ag after s.c. & 240 & 0.84 & - & 0.40 & 203.97
\end{tabular}


Table 2 Pharmacokinetic parameters from the two-compartmental model

\begin{tabular}{|c|c|c|c|c|c|c|c|}
\hline $\mathrm{Ag}$ after i.v. & Parameter units & AUC (h mg L $\left.{ }^{-1}\right)$ & $\begin{array}{l}\text { First half } \\
\text { life }(\mathrm{h})\end{array}$ & $\begin{array}{l}\text { Second half } \\
\text { life }(\mathrm{h})\end{array}$ & $C_{\max }\left(\mathrm{mg} \mathrm{L}^{-1}\right)$ & MRT (h) & $V_{\mathrm{ss}}(\mathrm{mL})$ \\
\hline Two compartments & Estimate & 383.31 & 0.032 & 193 & 44.61 & 277 & 288.85 \\
\hline
\end{tabular}

time curve did not decline smoothly as a linear line but as two different phases (i.e., distribution and elimination). Two compartments showed the best model fit for $\mathrm{Ag}$ concentrations from nanorods after i.v. injection. Fig. S5 $\dagger$ demonstrated the calculated model versus the obtained Ag concentrations for the i.v. group using two compartment model. Other groups were poorly fitted by compartmental models. Detailed results were showed in Table 2. The results showed that after i.v. injection, $\mathrm{Ag}$ from nanorods was cleared very fast within $10 \mathrm{~min}$ after nanorods entering the body $\left(t_{1 / 2}=0.032 \mathrm{~h}\right)$. Then it had a slow clearance phase with a half-life $193 \mathrm{~h}$.

In the present study, approximately $46 \%$ of $\mathrm{Ag}$ and $13 \%$ of $\mathrm{Au}$ (theoretical value: dosage $\times 100 \% /$ (rat's bodyweight $\times 7 \%$ (the proportion of blood to body weight in rats))) remained in blood at $3 \mathrm{~min}$ after i.v. injection, respectively. However, it decreased to $7 \%$ of $\mathrm{Ag}$ and $4 \%$ of $\mathrm{Au}$ in blood at $10 \mathrm{~min}$ after i.v. injection. The results demonstrated that after i.v. injection, they remained in blood with a very slow clearance till $14 \mathrm{~d}(336 \mathrm{~h})$. The twocompartment model also demonstrated that the second halflife of Ag was $193 \mathrm{~h}$ after i.v. injection. After s.c. injection, Ag concentrations were similar to i.v. injection after $336 \mathrm{~h}$. However, it did not have apparently clearance and even increased after $2 \mathrm{~d}$, which demonstrated the continuous release of Ag ions to blood for the s.c. injected nanorods in rats.

\subsection{Tissue distribution of $\mathrm{Ag}$ and $\mathrm{Au}$ after i.v. injection of Au@Ag NRs}

Nearly 30 organs were harvested at $24 \mathrm{~h}$ after a single i.v. injection of Au@Ag NRs. Table 3 provided the whole data from all tested organs. There was the highest level of Ag in liver, followed by portal nodes, spleen, lung, bone marrow and pancreas. Ag was rarely distributed in other organs including kidney, heart, brain, stomach etc. On the whole, the distribution pattern of Ag was similar to other labs' studies, ${ }^{16-18,20}$ confirming that liver and spleen may be the major target organs for nanoparticle accumulation, especially after intravenous administration. ${ }^{28} \mathrm{Au}$ was also mainly accumulated in liver, portal nodes, spleen and bone marrow, while there was extremely low level of $\mathrm{Au}$ in some other organs, especially in brain (Table 3). It was worth noting that $\mathrm{Ag}$ or Au largely accumulated in some special lymph nodes such as portal nodes, which was also confirmed by TEM images as shown in Fig. 5A. This result indicated that Au@Ag NRs can successfully enter lymphatic system, which has not been previously reported. Furthermore, EDS mapping results displayed that a few of Au nanorods were still coated by a small quantity of $\mathrm{Ag}$ and there were also some free $\mathrm{Ag}$ around $\mathrm{Au}$ nanorods (Fig. 5B). It indicated that a majority of $\mathrm{Ag}$ had been released from nanorods. In addition, although the i.v. injection way may not be a relevant route of AgNPs exposure to consumers, this administration route can provide some valuable information about $\mathrm{Ag}$ behaviours in vivo for traversing the primary internal barriers (e.g. skin, lung and so on) after adminstration. ${ }^{15} \mathrm{Au}$ content in brain was too low to be detected, suggesting that Au@Ag NRs cannot cross over the blood-brain barrier (BBB) at $24 \mathrm{~h}$ after i.v. injection. This result is quite different from several previous studies which have claimed that AgNPs could traverse BBB as particles and accumulate in the brain. ${ }^{19,29,30}$ Possible explanation could be the different shapes and different surface groups of nanoparticle samples. Anyway, in our case, the reliable ICP-MS method gives strong confidence in the accuracy of measurement for $\mathrm{Ag}$ or $\mathrm{Au}$ content in tissues. We also noticed that the $\mathrm{Ag} / \mathrm{Au}$ ratio also changes in different tissues. For instance, the $\mathrm{Ag} / \mathrm{Au}$ ratios in lung, pancreas and ileum were much higher than in liver or spleen. It may indicate different release behaviours or accumulation trends of $\mathrm{Ag}^{+}$in different tissues. In addition, these two organs (liver and spleen) are responsible for the particle removal from the blood

Table 3 The content of $\mathrm{Ag}$ and $\mathrm{Au}$ in different organs at $24 \mathrm{~h}$ after i.v. injection

i.v. injection ( $n=8$, including 4 males and 4 females)

\begin{tabular}{lcc} 
Organs & $\mathrm{Ag}$ content $\left(\mu \mathrm{g} \mathrm{g}^{-1}\right)$ & $\mathrm{Au}$ content $\left(\mu \mathrm{g} \mathrm{g}^{-1}\right)$ \\
\hline Inguinal nodes & $2.31 \pm 0.92$ & $0.11 \pm 0.05$ \\
Iliac nodes & $3.58 \pm 1.07$ & $0.65 \pm 1.72$ \\
Portal nodes & $160.64 \pm 27.88$ & $159.18 \pm 29.24$ \\
Superior mesenteric nodes & $11.80 \pm 9.58$ & $0.81 \pm 0.67$ \\
Axillary nodes & $2.17 \pm 1.03$ & $0.32 \pm 0.25$ \\
Facial nodes & $3.23 \pm 1.15$ & $1.60 \pm 0.73$ \\
Parathymic nodes & $1.81 \pm 1.09$ & 0 \\
Testis & $0.52 \pm 0.10$ & $0.10 \pm 0.06$ \\
Uterus & $3.66 \pm 0.56$ & $0.16 \pm 0.03$ \\
Epididymis & $1.97 \pm 0.53$ & $0.70 \pm 0.23$ \\
Ovary & $2.04 \pm 1.28$ & $0.76 \pm 0.06$ \\
Kidney & $3.35 \pm 1.44$ & $0.58 \pm 0.33$ \\
Adrenal gland & $5.26 \pm 1.94$ & $3.36 \pm 1.43$ \\
Spleen & $36.64 \pm 10.46$ & $37.58 \pm 9.64$ \\
Liver & $165.44 \pm 58.61$ & $727.34 \pm 757.46$ \\
Thymus & $1.27 \pm 0.19$ & $0.36 \pm 0.14$ \\
Heart & $1.24 \pm 0.30$ & $0.48 \pm 0.112$ \\
Lung & $26.51 \pm 12.43$ & $9.65 \pm 2.58$ \\
Brain & $0.87 \pm 0.83$ & $0.02 \pm 0.03$ \\
Bladder & $5.36 \pm 3.44$ & $0.17 \pm 0.11$ \\
Stomach & $2.97 \pm 1.65$ & $0.08 \pm 0.010$ \\
Pancreas & $24.50 \pm 23.06$ & $0.40 \pm 0.21$ \\
Ileum & $16.58 \pm 13.67$ & $0.33 \pm 0.18$ \\
Colon & $2.19 \pm 0.81$ & $0.54 \pm 0.39$ \\
Skeletal muscle & $1.64 \pm 0.94$ & $0.19 \pm 0.134$ \\
Fat & $0.81 \pm 0.57$ & $0.34 \pm 0.30$ \\
Bone marrow & $24.67 \pm 13.61$ & $15.16 \pm 4.40$ \\
& &
\end{tabular}




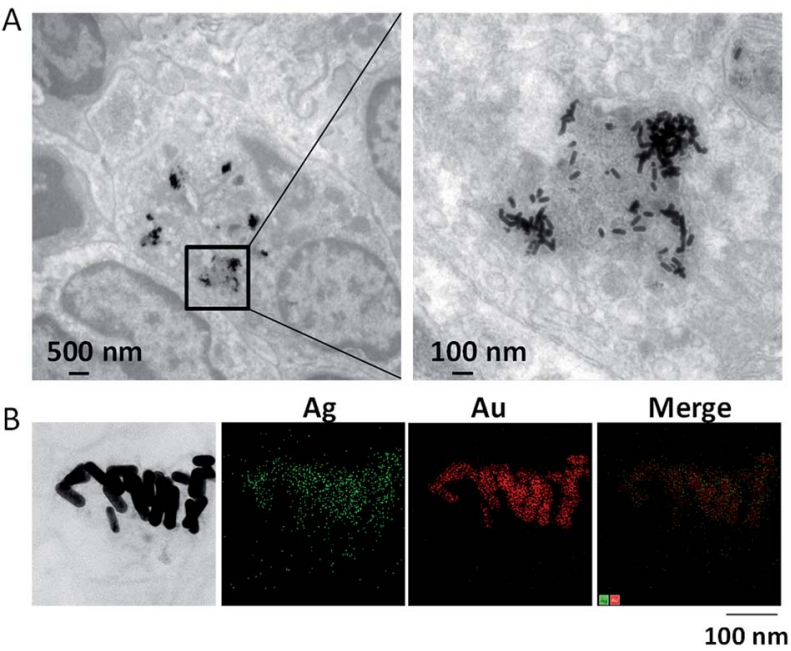

Fig. 5 The distribution of Au@Ag NRs in portal lymph nodes at $24 \mathrm{~h}$ after a single i.v. injection of Au@Ag NRs. (A) TEM images. (B) EDS mapping images.

circulation. So the accumulation of Au@Ag NRs might also explain the high levels of Au compared to the Ag levels, especially in the liver.

\subsection{Gender-related tissue distribution after s.c. administration of Au@Ag NRs}

Furthermore, for s.c. administration, the contents of $\mathrm{Ag}$ and $\mathrm{Au}$ in all tested organs were generally lower than those after i.v. injection (Table $\mathrm{S} 1 \dagger$ ). This implies that the nanorods may not easily migrate from subcutis towards blood circulation and then distribute systemically to other tissues. However, we found the gender-related tissue distribution of $\mathrm{Ag}$, especially after s.c. injection of Au@Ag NRs. As shown in Fig. 6 and Table 4, in almost all detected organs, the accumulation of $\mathrm{Ag}$ in female rats was more than that in male rats. In a previous report, they only found there were sex-dependent differences in kidneys after 28 day oral administration. ${ }^{31}$ However, in our case, there were many other important organs with higher accumulation of $\mathrm{Ag}$ in females compared with that in males, which has not been previously reported. Especially in adrenal gland and heart, Ag deposition in females were about 78-fold and 151-fold more than that in males, respectively. It is yet still unknown about the influence of AgNPs or $\mathrm{Ag}^{+}$on the secretion of adrenaline in female animals as well as heart diseases. For i.v. administration way, only in a few of organs including superior mesenteric nodes, lung, bladder and pancreas, the Ag content in female rats was higher than that in male rats (Fig. S6 and Table $\mathrm{S} 2 \dagger$ ). But only in lungs there were significant differences between males and females. This is consistent with a previous study in which lungs were also reported with significantly higher levels of $\mathrm{Ag}$ in female mice compared with male ones following a 14 day i.v. injection. ${ }^{8}$ Therefore, further research concerning the specific mechanisms of sex-related different tissue distribution of AgNPs would be warranted. Additionally, to be interesting, there was more $\mathrm{Au}$ accumulation in male livers than that in female ones after i.v. injection (Table $\mathrm{S} 2 \dagger$ ). These results suggest that different administration ways may lead to various genderrelated distributions of different nanomaterials.

In addition, we have also done the comparisons between i.v. and s.c. injections for male and female groups, separately (Table 4 and Table $\mathrm{S} 2 \dagger$ ). As expected, it showed the typical pattern of i.v. vs. s.c. injection. There were much more content of $\mathrm{Ag}$ or $\mathrm{Au}$ in most tissues after i.v. injection than that after s.c. injection since the s.c. injected $\mathrm{Ag}$ or $\mathrm{Au}$ had to break through various barriers before getting into blood vessels. However, the content of $\mathrm{Ag}$ as well as $\mathrm{Au}$ in axillary nodes of male rats displayed the opposite pattern. The possible reason might be due

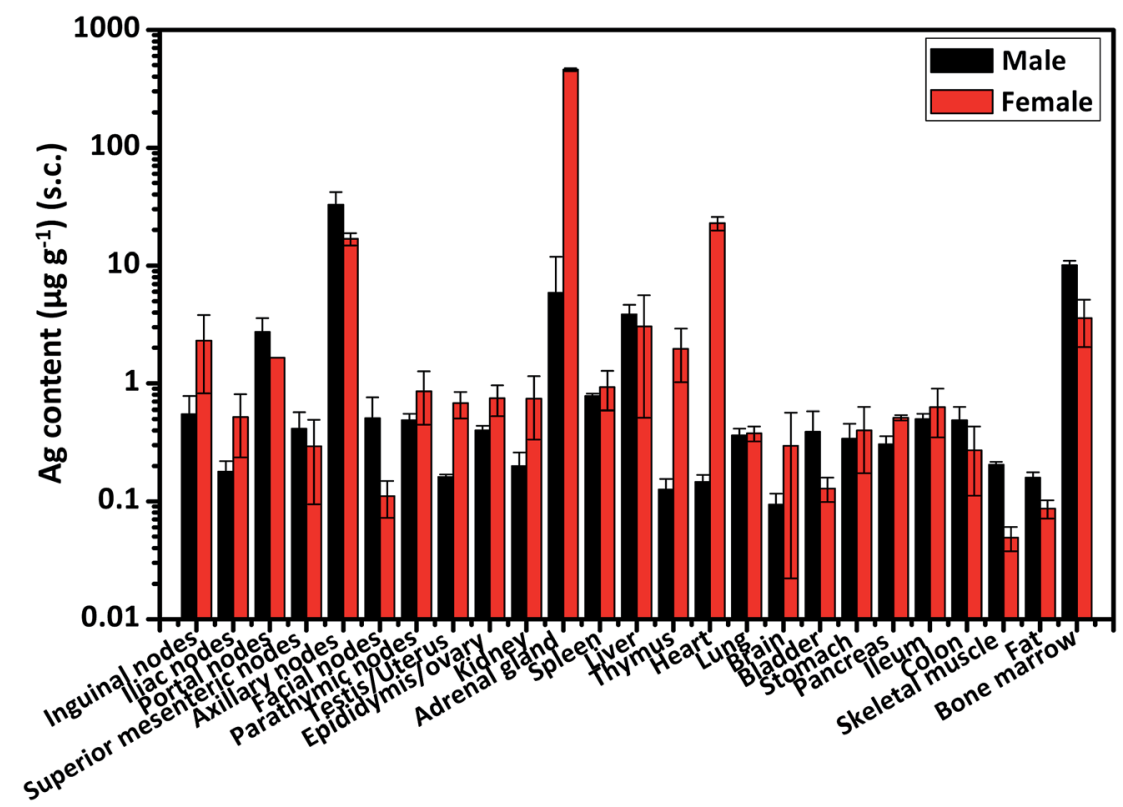

Fig. 6 The content of $\mathrm{Ag}$ in male and female organs at $24 \mathrm{~h}$ after s.c. injection. All data were deducted by the background value from blank organs. 
Table 4 The gender-related distribution of $\mathrm{Ag}$ and $\mathrm{Au}$ in different organs at $24 \mathrm{~h}$ after s.c. injection ${ }^{a}$

s.c. injection ( $n=8$ including 4 males and 4 females)

\begin{tabular}{|c|c|c|c|c|}
\hline \multirow[b]{2}{*}{ Organs } & \multicolumn{2}{|c|}{$\mathrm{Ag}$ content $\left(\mu \mathrm{g} \mathrm{g}^{-1}\right)$} & \multicolumn{2}{|c|}{ Au content $\left(\mu \mathrm{g} \mathrm{g}^{-1}\right)$} \\
\hline & Male & Female & Male & Female \\
\hline Inguinal nodes & $0.55 \pm 0.23$ & $2.31 \pm 1.49$ & 0 & 0 \\
\hline Iliac nodes & $0.18 \pm 0.04$ & $0.52 \pm 0.28$ & 0 & 0 \\
\hline Portal nodes & $2.74 \pm 0.85$ & 1.65 & 0 & 0 \\
\hline Superior mesenteric nodes & $0.41 \pm 0.16$ & $0.29 \pm 0.20$ & 0 & 0 \\
\hline Axillary nodes & $32.68 \pm 9.41$ & $16.77 \pm 1.97$ & $2.30 \pm 1.88$ & 0 \\
\hline Facial nodes & $0.51 \pm 0.25$ & $0.11 \pm 0.04$ & 0 & 0 \\
\hline Parathymic nodes & $0.49 \pm 0.06$ & $0.86 \pm 0.41$ & 0 & 0 \\
\hline Testis/uterus & $0.16 \pm 0.01$ & $0.68 \pm 0.17$ & 0.06 & $0.05 \pm 0.04$ \\
\hline Epididymis/ovary & $0.40 \pm 0.04$ & $0.74 \pm 0.21$ & $0.14 \pm 0.07$ & $0.03 \pm 0.02$ \\
\hline Kidney & $0.20 \pm 0.06$ & $0.74 \pm 0.41$ & $0.26 \pm 0.22$ & 0.05 \\
\hline Adrenal gland & $5.92 \pm 6.06$ & $459.73 \pm 12.66^{* *}$ & 0 & 0 \\
\hline Spleen & $0.78 \pm 0.04$ & $0.93 \pm 0.34$ & $0.44 \pm 0.34$ & $0.01 \pm 0.01$ \\
\hline Liver & $3.85 \pm 0.80$ & $3.06 \pm 2.55$ & $2.14 \pm 1.82$ & $0.02 \pm 0.02$ \\
\hline Thymus & $0.13 \pm 0.03$ & $1.97 \pm 0.95$ & $0.03 \pm 0.03$ & $0.12 \pm 0.06$ \\
\hline Heart & $0.15 \pm 0.02$ & $22.76 \pm 2.99^{* *}$ & $0.02 \pm 0.02$ & $0.03 \pm 0.03$ \\
\hline Lung & $0.36 \pm 0.05$ & $0.38 \pm 0.06$ & $0.05 \pm 0.02$ & $0.07 \pm 0.06$ \\
\hline Brain & $0.09 \pm 0.02$ & $0.30 \pm 0.27$ & 0 & 0 \\
\hline Bladder & $0.39 \pm 0.19$ & $0.13 \pm 0.03$ & $0.05 \pm 0.04$ & 0 \\
\hline Stomach & $0.34 \pm 0.12$ & $0.40 \pm 0.23$ & $0.22 \pm 0.18$ & 0 \\
\hline Pancreas & $0.31 \pm 0.05$ & $0.51 \pm 0.03$ & $0.11 \pm 0.04$ & 0 \\
\hline Ileum & $0.50 \pm 0.06$ & $0.63 \pm 0.28$ & 0.01 & 0 \\
\hline Colon & $0.49 \pm 0.14$ & $0.27 \pm 0.16$ & $0.10 \pm 0.08$ & $0.03 \pm 0.02$ \\
\hline Skeletal muscle & $0.21 \pm 0.01$ & $0.05 \pm 0.01$ & $0.06 \pm 0.02$ & 0 \\
\hline Fat & $0.16 \pm 0.02$ & $0.09 \pm 0.02$ & $0.03 \pm 0.00$ & $0.01 \pm 0.01$ \\
\hline Bone marrow & $10.12 \pm 0.90$ & $3.59 \pm 1.56$ & 0 & 0.13 \\
\hline
\end{tabular}

to the accumulation of phagocytes which phagocytosed $\mathrm{Au} @ \mathrm{Ag}$ NRs in the draining lymph nodes. Some published papers reported the similar results for other nanomaterials but not silver nanomaterials. A part of multi-walled carbon nanotubes (MWCNTs) injected subcutaneously into mice were engulfed by macrophages in the injection site and then carried away by these macrophages to enter the lymph nodes via the lymph ducts. ${ }^{32}$ Another group also reported that lymph nodes could collect a lot of AuNPs. ${ }^{33}$ In addition, the level of Ag, especially in adrenal gland of female rats was much higher than that in i.v. injection. The cause of this abnormality is not yet clear. We plan to do more experiments to explore it in the future.

\section{Conclusions}

Taken together, in this study, we have established an accurate and reliable ICP-MS method for measuring Ag and Au concentrations in biological tissues with a very low detection limit $\left(0.005 \mu \mathrm{g} \mathrm{g}^{-1}\right.$ for $\mathrm{Ag}$ and $0.015 \mu \mathrm{g} \mathrm{g}^{-1}$ for $\mathrm{Au}$ in blood; $0.020 \mu \mathrm{g}$ $\mathrm{g}^{-1}$ for $\mathrm{Ag}$ and $0.015 \mu \mathrm{g} \mathrm{g}^{-1}$ for Au in liver) and good linearity up to $500 \mu \mathrm{g} \mathrm{g}^{-1}$. Further, this method has been used to analyze $\mathrm{Ag}$ or Au distribution in rat blood and organs after an i.v or s.c. administration of Au@Ag NRs. The time-dependent contents of $\mathrm{Ag}$ and $\mathrm{Au}$ in blood were investigated and two-related pharmacokinetic models have been constructed for quantitative bioavailability evaluation of AgNPs according to the measured $\mathrm{Ag} / \mathrm{Au}$ contents in blood. There was the highest level of $\mathrm{Ag}$ in liver, followed by portal nodes, spleen, lung, bone marrow and pancreas at $24 \mathrm{~h}$ after i.v. injection. More importantly, we first found there were different gender-related distribution of $\mathrm{Ag}$ and $\mathrm{Au}$ in some organs, especially after s.c. injection. These important results can help us to evaluate and identify related biological risks of silver as well as gold nanomaterials.

\section{Conflicts of interest}

There are no conflicts to declare.

\section{Acknowledgements}

This study is financially supported by "Strategic Priority Research Program" of Chinese Academy of Sciences (XDA09040300) and the National Key Research and Development Program of China (2016YFA0200900, 2016YFA0200903).

\section{Notes and references}

1 S. K. Singh, K. Goswami, R. D. Sharma, M. V. Reddy and D. Dash, Int. J. Nanomed., 2012, 7, 1023.

2 M. Ahamed, M. S. Alsalhi and M. K. Siddiqui, Clin. Chim. Acta, 2010, 411, 1841.

3 R. A. Sperling, G. P. Rivera, F. Zhang, F. M. Zanella and W. J. Parak, Chem. Soc. Rev., 2008, 37, 1896.

4 E. Boisselier and D. Astruc, Chem. Soc. Rev., 2009, 38, 1759. 
5 H. Zhou, P. Jiao, L. Yang, X. Li and B. Yan, J. Am. Chem. Soc., 2011, 133, 680.

6 X. Li, H. Zhou, L. Yang, G. Du, A. S. Pai-Panandiker, X. Huang and B. Yan, Biomaterials, 2011, 32, 2540.

7 H. J. Johnston, G. Hutchison, F. M. Christensen, S. Peters, S. Hankin and V. Stone, Crit. Rev. Toxicol., 2010, 40, 328.

8 Y. Xue, S. Zhang, Y. Huang, T. Zhang, X. Liu, Y. Hu, Z. Zhang and M. Tang, J. Appl. Toxicol., 2012, 32, 890.

9 R. Zhang, Y. Bai, B. Zhang, L. Chen and B. Yan, J. Hazard. Mater., 2012, 211, 404.

10 Q. Mu, G. Jiang, L. Chen, H. Zhou, D. Fourches, A. Tropsha and B. Yan, Chem. Rev., 2014, 114, 7740.

11 X. Zhang, W. Shen and S. Gurunathan, Int. J. Mol. Sci., 2016, 17, 1603.

12 K. B. Riaz Ahmed, A. M. Nagy, R. P. Brown, Q. Zhang, S. G. Malghan and P. L. Goering, Toxicol. In Vitro, 2017, 38, 179.

13 D. P. Lankveld, A. G. Oomen, P. Krystek, A. Neigh, A. Troostde Jong, C. W. Noorlander, J. C. Van Eijkeren, R. E. Geertsma and W. H. De Jong, Biomaterials, 2010, 31, 8350.

14 K. Park, E. J. Park, I. K. Chun, K. Choi, S. H. Lee, J. Yoon and B. C. Lee, Arch. Pharm. Sci. Res., 2011, 34, 153.

15 C. Recordati, M. De Maglie, S. Bianchessi, S. Argentiere, C. Cella, S. Mattiello, F. Cubadda, F. Aureli, M. D'Amato, A. Raggi, C. Lenardi, P. Milani and E. Scanziani, Part. Fibre Toxicol., 2016, 13, 12.

16 J. Meng, Y. Ji, J. Liu, X. Cheng, H. Guo, W. Zhang, X. Wu and H. Xu, Nanotoxicology, 2014, 8, 686.

17 M. van der Zande, R. J. Vandebriel, E. Van Doren, E. Kramer, Z. Herrera Rivera, C. S. Serrano-Rojero, E. R. Gremmer, J. Mast, R. J. Peters, P. C. Hollman, P. J. Hendriksen, H. J. Marvin, A. A. Peijnenburg and H. Bouwmeester, ACS Nano, 2012, 6, 7427.

18 W. H. De Jong, L. T. Van Der Ven, A. Sleijffers, M. V. Park, E. H. Jansen, H. Van Loveren and R. J. Vandebriel, Biomaterials, 2013, 34, 8333.
19 S. C. G. Kiruba Daniel, V. Tharmaraj, T. Anitha Sironmani and K. Pitchumani, Appl. Clay Sci., 2010, 48, 547.

20 D. K. Tiwari, T. Jin and J. Behari, Toxicol. Mech. Methods, 2011, 21, 13.

21 A. A. Ammann, J. Mass Spectrom., 2007, 42, 419.

22 Y. Nia, S. Millour, L. Noel, P. Krystek, W. D. Jong and T. Guérin, J. Nanomed. Nanotechnol., 2015, 6, 1.

23 D. P. Lankveld, R. G. Rayavarapu, P. Krystek, A. G. Oomen, H. W. Verharen, T. G. van Leeuwen, W. H. De Jong and S. Manohar, Nanomedicine, 2011, 6, 339.

24 K. C. Black, Y. Wang, H. P. Luehmann, X. Cai, W. Xing, B. Pang, Y. Zhao, C. S. Cutler, L. V. Wang, Y. Liu and Y. Xia, ACS Nano, 2014, 8, 4385.

25 Y. Xiang, X. Wu, D. Liu, Z. Li, W. Chu and L. Feng, Langmuir, 2008, 24, 3465.

26 Johan Gabrelsson, Pharmacokinetic and Pharmacodynamic Data Analysis: Concepts and Applications, 4th Edition, Swedish Pharmaceutical Press, ISBN: 9789197651004, 2007.

27 FDA, Bioavailability and Bioequivalence Studies Submitted in NDAs or INDs-General Considerations, Guidance for Industry, Rockville, MD, 2014.

28 A. Chrastina and J. E. Schnitzer, Int. J. Nanomed., 2010, 5, 653.

29 J. Tang, L. Xiong, S. Wang, L. Liu, J. Li, F. Yuan and T. Xi, J. Nanosci. Nanotechnol., 2009, 9, 4924.

30 H. S. Sharma, S. Hussain, J. Schlager, S. F. Ali and A. Sharma, Acta Neurochirurgica Supplementum, 2010, 106, 359.

31 Y. S. Kim, J. S. Kim, H. S. Cho, D. S. Rha, J. M. Kim, J. D. Park, B. S. Choi, R. Lim, H. K. Chang, Y. H. Chung, I. H. Kwon, J. Jeong, B. S. Han and I. J. Yu, Inhalation Toxicol., 2008, 20, 575 .

32 J. Meng, M. Yang, F. Jia, Z. Xu, H. Kong and H. Xu, Nanotoxicology, 2011, 5, 583.

33 K. E. Carr, R. A. Hazzard, S. Reid and G. M. Hodges, Pharm. Res., 1996, 13, 1205. 